\title{
Memória da economia: a defesa do capital industrial pela economia política clássica
}

\author{
Igor Zanoni Constant Carneiro Leão*
}

RESUMO - Este texto discute a dissolução da economia política clássica e sua defesa do capital industrial e do trabalho produtivo, assinalando a controvérsia com os defensores da grande propriedade fundiária na Inglaterra. Além disso, indica como sua substituição pela economia convencional se fez em um ambiente de defesa dos interesses financeiros nascidos à época da segunda revolução industrial e do nascimento da grande empresa moderna. Analisa ainda a importância dessa discussão na crise que o capitalismo global vive atualmente.

Palavras-chave: Economia política. Trabalho. Capital produtivo. Crise.

A longa transição do Antigo Regime para a sociedade burguesa foi completada em finais do século XVIII, na Inglaterra, pela sua industrialização originária. Entre esse período e 1840, aproximadamente, a economia política inglesa teve de defender de forma árdua e contundente os interesses do capital industrial para que ele também ganhasse uma preeminência política contra os interesses remanescentes do antigo feudalismo. Vejamos os traços principais desse período.

Em Adam Smith, na Riqueza das Nações, a defesa da indústria vai junto com a defesa dos trabalhadores e da própria moral que reina nas cidades onde ela domina. Assim, para ele, as "classes inferiores" do povo, nas cidades manufatureiras inglesas e holandesas, onde são empregadas, sobretudo pelos capitais industriais, são, em regra, diligentes, sóbrias e parcimoniosas, enquanto nas cidades onde essas classes ainda se prendem às antigas cortes, vivem à custa das rendas dissipadas e são em geral preguiçosas, dissolutas e pobres. A defesa da população assalariada pelo capital industrial nascente vai, pois junto com a defesa do trabalho produtivo, que gera lucros, acumulação e riqueza, bem como junto com uma censura ao trabalho improdutivo que cerca os extratos remanescentes do Antigo Regime.

Ainda para Smith, o capital é sinônimo de diligência, e todo acréscimo ou decréscimo de capital tende a aumentar ou a diminuir a quantidade dos trabalhadores produtivos moralmente superiores ao mesmo tempo em que aumenta o produto anual da terra e do trabalho do país, a riqueza e a renda real de todos os habitantes. Os fundos

\footnotetext{
* Doutor em Economia pela UNICAMP. É professor associado do Departamento de Economia da
} Universidade Federal do Paraná. Endereço eletrônico: igorzaleao@yahoo.com.br. 
utilizados para emprego de trabalhadores produtivos, isto é, que produzem com seu trabalho cotidiano excedente para o capital e impulsiona os lucros e a acumulação que fazem a riqueza do país. Já os fundos gastos como uma renda improdutiva, isto é, destinada a manter trabalhadores improdutivos, tão característica do Antigo Regime, criam a prodigalidade e a dissipação públicas e devem ser reduzidos ao mínimo necessário, na Corte, na Igreja, na Marinha ou no Exército, uma vez que esses trabalhadores, nada produzindo eles mesmos, são sustentados pelo trabalho dos outros. O contexto em que Smith se situa é econômico e moral.

A maior riqueza das nações com acréscimo do capital produtivo faz com que os trabalhadores achem emprego com facilidade, eleva os seus salários e põe limites aos lucros. Os trabalhadores produtivos, em Smith, são aqueles ocupados na agricultura, na manufatura, no grande comércio e no comércio varejista. As pessoas cujo trabalho se exerce nesses ramos em regra acrescentam ao preço dos objetos que manejam o valor de sua própria manutenção e consumo pessoal, além de um excedente.

Também em David Ricardo se encontra a distinção entre trabalho produtivo e improdutivo, estabelecida por Smith, segundo a qual o primeiro se troca diretamente por capital e o segundo por renda. Entretanto, está distante de elogiar os trabalhadores produtivos como este autor. Para Ricardo, trabalhador produtivo é alguém reduzido a mero instrumento de produção de riqueza alheia e, se a mesma quantidade de riqueza alheia pode ser gerada com número menor de trabalhadores produtivos, estes podem ser reduzidos.

Ainda para Ricardo o capital tende a reduzir a um mínimo decrescente o tempo de trabalho necessário para produzir as mercadorias e, portanto, a população produtiva, em relação à quantidade de produto. Todavia, a nova economia que se vai instalando tem a tendência de acumular, converter lucro em capital, apropriar-se da maior quantidade possível de trabalho alheio. Procura rebaixar os salários, mas aumentar ao máximo o emprego. Daí o elogio de Ricardo ao capital produtivo que, aumentando ao máximo o excedente líquido, aumenta o emprego e a acumulação, bem como a riqueza da nação, como diria Smith.

$\mathrm{Na}$ medida em que aceita com Malthus o chamado princípio da população, segundo o qual o crescimento da população é limitado pelo crescimento mais lento dos bens agrícolas destinados a sua subsistência, Ricardo afirma que os trabalhadores devem desejar salários moderados para que o excedente deles tome a forma de capital aumentando o emprego. Caso os salários subam além de certo ponto, cresce a população e diminui o excedente e a acumulação. Há, assim, uma oscilação entre o lucro e os salários resolvida se a população trabalhadora refrear sua reprodução de modo a que seu crescimento apenas acompanhe a 
acumulação do capital. Ricardo, aí, lembra as exortações do pároco Malthus sobre a moralidade e a continência dos trabalhadores.

Como se sabe, todavia, a argumentação de Ricardo a favor dos lucros do capital choca-se com a defesa de Malthus da necessidade de se manter, na sociedade, uma classe de rentistas ociosos para evitar superacumulação e para que a propriedade tenha uma defesa adequada. Esta discussão ocorre em torno da necessidade de se abolir restrições à importação de grãos pela Inglaterra, com o fim de defender os lucros do aumento dos salários e permitir que a acumulação não seja detida.

Fica claro, assim, que a defesa do capital aplicado em atividades produtivas, ou seja, em atividades que empreguem trabalhadores produtivos é um dos pontos principais na defesa da nova sociedade contra a letargia do período medieval ainda presente no Antigo Regime, como um modo de produção transitório e heterogêneo com barreiras claras à acumulação, entre as quais estava a presença de uma classe de proprietários ociosos monopolizando as terras agrícolas mais férteis. Esta classe ainda estava no comando do Estado mesmo avançada a industrialização, ao tempo de Malthus e Ricardo.

$\mathrm{Na}$ Inglaterra a defesa da indústria e do trabalho produtivo tomou, pois uma orientação política definida contra o status quo, e foi radicalizada pelos chamados socialistas ricardianos ou sindicalistas que defendiam o direito dos trabalhadores ao conjunto do produto, uma vez que todo ele se devia ao trabalho produtivo. Essas formas de embate político levaram cedo a uma dissolução da economia política cujos maiores expoentes foram Adam Smith e Ricardo. A rigor a economia política só seria levada adiante de forma crítica com Marx, e reaparece nas preocupações centrais dos grandes autores que compreenderam os nexos inerentes ao funcionamento das sociedades mercantis e empresariais.

Relatando um pouco a reação contra as implicações sociais da doutrina ricardiana, já em 1804, o Conde Lauderdale, segundo Marx, fazia uma justificação do lucro baseada na idéia de que este provinha dos próprios capitais, porque estes "substituem" trabalho que o homem teria de fazer com as próprias mãos. O Conde mostra-se inimigo da teoria de Smith sobre acumulação e poupança e a distinção entre trabalhadores produtivos e improdutivos. Outros economistas, como Malthus, aceitaram a distinção entre trabalhadores produtivos e improdutivos, mas procuraram mostrar que ambos são igualmente necessários à produção da riqueza material.

Na medida, porém, em que, a partir de 1815, Ricardo começa a escrever e a colocar a economia política de forma mais articulada e com menos rodeios do que Smith, entre as 
décadas de 20 e 30, do século XIX, assiste-se a uma vigorosa reação contra o pensamento ricardiano. Segundo Maurice Dobb, em 1831 Torrens afirmou em uma discussão no Clube de Economia Política que "todos os grandes princípios da obra de Ricardo foram sucessivamente abandonados, e que todas as suas teorias sobre o Valor, Renda e o Lucro eram agora geralmente consideradas errôneas".

O mais influente ataque contra Ricardo foi a obra de Samuel Bailey em 1825 criticando a noção ricardiana de valor baseada no trabalho incorporado na mercadoria e na busca por uma medida invariável de valor. Afirmou que valor em seu sentido último significa a estima em que qualquer objeto é tido e indica um efeito produzido na mente. $\mathrm{O}$ valor do bem produzido seria determinado pela quantidade de capital aplicada e nega a oposição entre salários e lucros, tomando evidentemente salários reais e não salários no sentido de Ricardo, isto é, a proporção de trabalho necessária para produzir o salário do trabalhador.

Também a renda é tratada por Bailey como um exemplo de "valor de monopólio" devido a escassez de terras de fertilidade superior e resulta do lucro extraordinário conferido pela posse de um instrumento de produção protegido até certo ponto da concorrência. Ao lado de outros tipos de monopólio o monopólio da terra significa um caso em que a concorrência não pode aumentar exceto provocando aumento de custo.

As discussões do período envolveram figuras importantes na economia política inglesa como Malthus e James Mill, ainda de alguma forma ligados a Ricardo, mas o seu resultado foi o afastamento crescente das idéias ricardianas. Esse afastamento foi realçado entre 1834 e 1836 com as obras de Longfield e Nassau Sênior. O primeiro defendia que os lucros se deviam à produtividade adicional extraída do trabalho quando o capital era investido em máquinas, avançando já a idéia de produtividade marginal do capital. O segundo pensou o lucro como a recompensa de uma abstinência colocando as bases para uma teoria do capital que seria aproveitada por economistas subseqüentes. Sênior postulava que "o lucro é a remuneração de uma abstinência, e esta o adiamento da satisfação" ao mesmo tempo em que o capital "deve a este fenômeno sua existência e conservação".

Ainda seguindo Maurice Dobb nesta explanação, Sênior defendia que o Trabalho e a Natureza são as únicas forças produtivas primárias e que atingem sua eficiência graças à presença da Abstinência. Por outro lado defende que o salário está ligado à produtividade do trabalhador e que a proporção de trabalhadores necessária para produzir bens-salários não determina os lucros na relação com os salários, mas a procura de trabalho em termos reais. Sênior defende ainda a idéia de Valor como ligada à Utilidade: "a Utilidade não indica 
nenhuma qualidade intrínseca às coisas a que chamamos útil, exprime apenas as suas relações com os trabalhos e prazeres da humanidade... não só há limites para o prazer que os bens de qualquer tipo podem proporcionar, como também o prazer diminui, numa proporção rapidamente crescente, muito antes desses limites;... dois artigos do mesmo tipo raramente proporcionam duas vezes o mesmo prazer que um" ( citação de Dobb ).

Por sua vez Longfield ataca a afirmação de Ricardo de que a taxa de lucros só pode ser compreendida no âmbito da baixa dos rendimentos da terra, que, elevando os custos de subsistência, faz subir os Salários. Para ele, "em qualquer caso, os lucros do capital serão sempre regulados por aquela parte que for forçoso aplicar com a menor eficiência no auxílio ao trabalho". Por outro lado os salários reais dependem da taxa de lucros e da eficiência do trabalho na produção dos artigos em que os salários são gastos.

Vários outros autores insistiram em idéias semelhantes, avançando uma teoria do valor relativo e uma teoria do capital ligada à abstinência, escapando da idéia de capital enquanto trabalho acumulado bem como afirmando a determinação da demanda pela utilidade dos bens. A idéia do capital ligado à abstinência reaparecerá mais tarde na teoria econômica como uma relação entre consumo presente e consumo futuro, como preferências intertemporais, bem como na idéia de que a poupança precede o investimento. Estas teses permanecerão na teoria neoclássica do investimento. Como se sabe, a teoria neoclássica começa a ser sistematizada e apresentada a partir de 1870 com Walras, Jevons e Menger, e têm uma formulação que talvez possa ser rotulada como mais rigorosa na obra de BohmBawerk.

Estas idéias foram decisivas contra a teoria ricardiana do excedente, no papel conflitivo da acumulação capitalista, face ás classes sociais. Há uma inclinação para um individualismo metodológico que desloca a idéia de sociedade e realça a de indivíduo, sendo que a própria idéia de sociedade mercantil é, a rigor, descartada em favor da subjetividade individual. Walras defenderá que a coleção de indivíduos atomizados pode realizar escolhas visando o equilíbrio geral. A discussão do funcionamento da economia capitalista passa a repousar na escolha racional de indivíduos que maximizam suas utilidades. Marx aponta para a dificuldade de essas idéias explicarem os nexos reais de uma economia capitalista, e nesse sentido toma-as como apologéticas ou vulgares, mas nas Teorias da Mais Valia não chega a discutir o seu desdobramento na chamada "revolução marginalista".

Mas Marx chega a discutir F.Bastiat, para quem a concorrência é um fator de harmonização de interesses e de escapar ao conflito entre as classes, recuperando de forma 
torcida a "mão invisível" de Adam Smith. Para este, a "mão invisível" compunha subjetividades contrapondo interesses conflitivos, mas agora se trata de retirar da economia a noção de conflito e a possibilidade de instabilidade. A idéia de uma economia baseada em uma dinâmica contraditória cede crescentemente lugar a um equilíbrio repondo continuamente as condições de funcionamento da economia.

O que me interessa aqui é realçar que a partir das décadas de trinta e quarenta do século dezenove as linhas fundamentais da economia política clássica são deixadas de lado, exceto por Marx e outro autores que fugirão das correntes centrais da economia. Em segundo lugar, que essas idéias vão nascendo aos poucos de forma não sistemática, pouco rigorosa, como crítica e afastamento de Smith e Ricardo. Afastamento que deixa ao largo noções fundamentais da economia política clássica como excedente, acumulação, trabalho produtivo e improdutivo e mesmo a noção de capital. Isto é verdadeiro também para a economia neoclássica. Como afirma Cláudio Napoleoni: “A razão de fundo do fracasso da teoria neoclássica do equilíbrio encontra-se na insuficiência do tratamento do significado e do papel do capital no processo econômico.(...) Mas o dado relativo ao capital( não importa se definido como um conjunto de grandezas,à maneira de Walras, ou como uma grandeza única,à maneira de Bohm-Bawerk) tem a particularidade de as suas mutações não dependerem de fatores externos, sendo antes a conseqüência do que sucede no interior do sistema considerado pela teoria e, precisamente, da produção de meios de produção.(..) A ação de modificação que o capital exerce sobre o sistema, esta espécie de feedback em que o produto aumenta a capacidade produtiva é naturalmente regida por regras, das quais a formação da taxa geral de lucro (ou de juro) representa o resultado global.Mas é evidente que esta regra não tem sentido e não pode realizar-se fora daquela ação; por isso, um esquema que, por um lado, elimina a ação do capital sobre o sistema e, por outro lado, pretende submeter o capital à regra da taxa geral de lucro, é um esquema necessáriamente incoerente, e as dificuldades matemáticas que se lhe deparam mais não são do que expressão dessa incoerência."

Em termos mais simples, há um problema se pensamos o capital como instrumentos de produção, pois isso dificulta a percepção da concorrência entre capitais e a formação de uma taxa média de lucros. Ao mesmo tempo, ainda se pensarmos o capital como uma única grandeza, essa formação da taxa geral de lucros se dá no âmbito da produção do capital e em seus efeitos sobre o produto e sobre a capacidade produtiva, o que está fora da visão neoclássica, que não apreende as mudanças no sistema econômico provocadas pela acumulação. 
É significativo que a ascensão das idéias anti-ricardianas se dê quando o capital já se torna dominante também no plano político e, a partir de 1870, quando nasce a economia neoclássica, novas industrializações como a americana, a alemã e a japonesa se dêem num contexto de nascimento da empresa moderna, de novas tecnologias altamente densas de capital e de fusão dos interesses entre o capital bancário e o industrial, sob dominância do primeiro, o chamado capital financeiro. Parece haver uma contradição entre a vitória do capital na vida real e sua precária problematização no plano da economia teórica dominante, embora sempre tenham surgido autores chamando a atenção para o novo e o significativo, mesmo quando não marxistas.

Uma resposta pode ser encaminhada inicialmente se lembramos os agudos conflitos políticos ao longo de todo o século dezenove, fazendo com que toda intervenção no plano teórico tivesse impactos no plano político. A economia se afirma como ciência, mas também como ideologia, em especial quando se afasta mais do que se aproxima dos nexos básicos em que vivem trabalhadores e capitalistas e a palavra ideologia toma o significado corrente de ocultamento do real. Ao mesmo tempo, qualquer arbitragem entre capital e trabalho fica fora de alcance e apenas no século vinte a política permitirá conciliações na forma de um mais ou menos amplo welfare state, à revelia de um liberalismo econômico que passa politicamente a um plano subordinado, especialmente após a Segunda Guerra ao mesmo tempo em que afirma um quase consenso neokeynesiano.

Um segundo encaminhamento à questão diz respeito ao fato de os adversários de Ricardo serem sobretudo homens ligados ao antigo establishment, defensores da grande propriedade agrária, da renda da terra e do gasto improdutivo. Ora, à medida que a importação de grãos pela Inglaterra fica liberada e os resquícios feudais desaparecem, essa defesa rentista do status quo parece sem sentido.

É possível todavia pensar que o capitalismo que sai da Segunda Revolução Industrial possui interesses bancários dominantes, e que embora o capital industrial se expanda fortemente após a Segunda Guerra, isto só foi possível no âmbito de um pacto internacional que limitou os interesses e a especulação com juros, câmbio e mercadorias. Em outras palavras, o capitalismo moderno tem uma face dominante rentista de tipo novo, financeira.

Assim, em sua importante crítica da economia neoclássica, Nicolai Bukharin afirma: “A evolução capitalista assistiu nas últimas décadas a uma rápida acumulação. como resultado do desenvolvimento das diferentes formas de crédito, a mais valia acumulada é apropriada por indivíduos que não têm amiúde nenhuma relação com a produção. O número desses 
indivíduos cresce continuamente, a ponto de chegar a formar uma classe social: a dos rentistas. Este estrato da burguesia, ainda que não constitua uma classe no sentido específico da palavra mas sobretudo um grupo com características próprias no interior da burguesia capitalista, apresenta certos traços distintivos que o caracterizam e que se derivam de sua “psicologia social". A extensão da sociedade por ações e da banca, e a crescente influencia da bolsa, engendra e consolida esse estrato social. Sua atividade econômica se exerce essencialmente no plano da circulação, sobretudo de títulos e valores, e nas transações bursáteis. É significativo o fato de que no interior deste estrato social, que vive das rendas que produzem eses valores, existam diferentes matizes; o caso limite está representado pela camada localizada fora não só da produção mas também do mesmo processo de circulação. Trata-se sobretudo dos possuidores de valores a juro fixo; rendas do Estado, obrigações de todo tipo etc.; em segundo lugar, daqueles que inverteram sua fortuna em bens de raiz, dos que obtém rendas seguras e duradouras."

Bukharin está defendendo a idéia de que o capitalismo financeiro, ou a fusão do capital bancário com o capital industrial sob dominância do primeiro, cria uma classe que se beneficia da produção e dos lucros, mas está separada da produção na medida em que não tem funções empresariais clássicas, sendo antes detentora de títulos que lhe dão direito à mais-valia formando um estrato com características próprias no interior da burguesia e vê o capitalismo sob a ótica de rendas derivadas desses títulos.

Para o autor, a economia marginalista é precisamente a que apresenta a economia do ponto de vista dos interesses e da visão de mundo desses rentistas de novo tipo, característicos da nova civilização financeira. Nesse sentido ganha significado a diluição das classes e da relação capital/trabalho operada por essa economia, pois o núcleo dinâmico do desenvolvimento e da acumulação, o capital industrial, está cercado por interesses representantes de um capital fictício que opera no interior do mecanismo de reprodução econômica e social. Nesse mesmo sentido Lênin falaria de um parasitismo característico do estádio monopolista do capital, que colocaria em segundo plano o capitalista industrial e o trabalhador produtivo.

Para mim, a defesa da propriedade e do rentista realizada por Malthus, Lauderdale e outros economistas tem uma atualidade que na verdade nunca perdeu, e obscurece ao mesmo tempo em que sua análise revela os laços reais em que se move política e economicamente o complexo mecanismo de acumulação de capital. Finalmente, creio que o momento que as economias capitalistas vivem em todo o mundo com a grande crise do início do século vinte e 
um tem ajudado a mostrar o avanço desses interesses rentistas ligados a uma expansão financeira sem respaldo na produção real, bem como seus efeitos deletérios sobre a sociedade global, ao mesmo tempo em que aponta a necessidade de sua regulação e de um novo pacto social entre capital, Estado e trabalho, a favor do desenvolvimento e contra a pobreza e as várias formas de exclusão.

\section{REFERÊNCIAS}

BELLUZO, L. G. de M. Aulas proferidas no Instituto de Economia da UNICAMP. Campinas, 1997. Notas de aula.

BUJARIN, N. La economia política del rentista. (Crítica de la economía marginalista). Córdoba y Buenos Aires: Pasado y Presente, 1977.

DOBB, M. Teorias do valor e distribuição desde Adam Smith. Rio de Janeiro: Martins Fontes, 1977.

KEYNES, J. M. A teoria geral do emprego, dos juros e da moeda. São Paulo: Abril, 1988.

LENINE, V. I. Imperialismo, estágio supremo do capitalismo. Coimbra: Centelha, 1974.

MARX, K. Teorias da mais-valia. Rio de Janeiro: Civilização Brasileira, 1980.

NAPOLEONI, C. O valor na ciência econômica. Rio de Janeiro: Martins Fontes, 1980.

RICARDO, D. Princípios de economia e tributação. São Paulo: Nova Cultural, 1988.

SMITH, A. A riqueza das nações. Rio de Janeiro: Civilização Brasileira, 1996. 
